\title{
A Cross-Cultural, Exploratory Study of Students' Reluctance to Attend Office Hours
}

\author{
Yassir Semmar \\ Qatar University
}

\begin{abstract}
The purpose of this study is to gain a better insight into the reasons that make Qatar University students reluctant to attend professors' office hours. Factor analysis was first conducted to reveal the components underlying this reluctance; Multivariate Analysis of Variance (MANOVA) was then employed to analyze the effects of gender, GPA, credit hours completed, year of enrollment, and college/major on those factors. Results indicated that professor's competence and demeanor, course characteristics, students' social skills, attitudes/motivation, time conflict/communication style, students' apprehension as well as their physical/emotional state were all related to their reluctance to attend office hours. Moreover the predictor variables of gender, GPA, and credit hours completed had significant effects on several of those seven reluctance factors.
\end{abstract}

\section{Introduction}

The bulk of research studies that have investigated the topic of faculty-student interaction outside of the classroom (e.g., during office hours) have largely been conducted in North American settings. Empirical investigations of the same phenomenon have received scarce attention in the Middle East. For instance, in the State of Qatar, studies examining students' attitudes and beliefs vis-à-vis attending office hours are non-existent at the secondary and postsecondary levels. At Qatar University, anecdotal evidence suggests a wide range of variability in students' willingness/reluctance to attend office hours.

Over the past four decades, researchers have demonstrated many advantages associated with the faculty-student transactions that take place outside the typical classroom. For example, Amenkhienan and Kogan (2004) found that faculty-student interaction during office hours had a positive impact on students' academic performance. This finding was also supported in a number of previous studies (e.g., Nadler \& Nadler, 2000; Atamian \& DeMoville, 1998; Pascarella \& Terenzini, 1991; Theophilides \& Terenzini, 1981; Pascarella, 1980; Pascarella et al., 1978; Spady, 1970; and Chickering, 1969). Other researchers have reported that students were more satisfied with their college experiences as a result of interacting with their professors (Astin, 1977; Pascarella \& Terenzini, 1976; Wilson et al., 1974; Wood \& Wilson, 1972; and Spady, 1971). Increased communication between students and faculty has also been linked to students' personal and intellectual development (Pascarella \& Terenzini, 1991; Chickering \& McCormick, 1973; and Chickering, 1972).

Given the relative importance of the aforementioned benefits associated with the interactions between faculty and students, and considering the fact that university students generally view teachers' accessibility (during office hours) as one of the essential characteristics of effective teachers (Onwuegbuzie et al., 2007), one might assume that students would not hesitate to engage in various communication transactions with their instructors outside of the classroom context. Nonetheless, there seems to be a persistent reluctance among Qatar University students to attend office hours in order to

Semmar, Y. (2009). A Cross-Cultural, Exploratory Study of Students' Reluctance to Attend Office Hours. 
receive the necessary help, which may be deemed critical to their academic success. Ryan, Gheen, and Midgley (1998) found that student characteristics (i.e., academic efficacy beliefs), teacher characteristics (i.e., social-emotional role), and classroom characteristics (i.e., classroom goal structure) were all related to students' avoidance of seeking help from their teachers.

\section{Purpose of the Study}

The purpose of this study was to:

(a) determine the factors that render Qatar University students reluctant to attend office hours,

(b) analyze whether variations of those reluctant factors exist in terms of students' gender, GPA, credit hours completed, year of enrollment, and college/major;

(c) gain new knowledge related to students' reluctance to attend office hours in a cross-cultural setting.

\section{Methodology}

This study involved two phases: The first descriptive phase employed exploratory factor analysis to examine the components that render students reluctant to attend office hours. The second phase of the study involved a causal-comparative design, in which the researcher assessed whether the components that emerged from factor analysis were linked to gender, GPA, year of enrollment, college/major, and credit hours completed.

205 participants (70 male, 135 female) completed a 40-item office hours questionnaire (OHQ) and a short demographics survey. $35 \%$ of the participants were males and $65 \%$ were females: this roughly 2:1 female to male ratio is typical of the student population that enrolls every semester at Qatar University.

The 40-item questionnaire used in this study was based on data obtained from student focus groups and an open-ended survey about students' resistance/reluctance to attend office hours as set forth by their professors. The questionnaire was initially constructed in Arabic, translated into English, and then backtranslated to Arabic. Cluster sampling was used to select participants from different sections of undergraduate psychology courses offered by the College of Education either as electives or general requirement courses. In cluster sampling, participants are selected in groups or clusters (i.e., sections); the sample consisted of participants within each of the selected sections or clusters. Cluster sampling represents a type of probability sampling that is used in cases where it may not be feasible to reach every individual in the population (Shadish et al., 2002).

Participants were asked to complete the questionnaire in a single class session. In addition, each participant was asked to complete a brief demographic survey. Participation was voluntary as reflected on the participants' informed consent forms signed by students prior to taking part in the study. After having completed the demographic information forms, participants were instructed to complete the 40item $\mathrm{OHQ}$, on which they indicated their agreement or disagreement with various statements on a sixpoint Likert scale (i.e., $6=$ strongly agree, $5=$ agree, $4=$ slightly agree, $3=$ slightly disagree, $2=$ disagree, $1=$ strongly disagree $)$.

\section{Research Question, Hypotheses, and Null Hypotheses}

Research Question: What components underlie students' reluctance to attend office hours?

Semmar, Y. (2009). A Cross-Cultural, Exploratory Study of Students' Reluctance to Attend Office Hours. Learning and Teaching in Higher Education: Gulf Perspectives 6(1). 
Research Hypothesis No. 1: Male and female students will have distinct reluctance factors.

Research Hypothesis No. 2: Students in different colleges will have different reluctance components.

Research Hypothesis No. 3: Juniors and seniors will have different reluctance factors compared to their freshmen and sophomore peers.

Research Hypothesis No. 4: Students with high GPAs will have different reluctance profiles compared to their peers with low GPAs.

Research Hypothesis No. 5: Students will have different reluctance components based on their year of enrollment at the university.

To assess the research hypotheses, this investigation tested the following five null hypotheses:

Null Hypothesis No. 1: There will be no difference between the reluctance factors of male and female students.

Null Hypothesis No. 2: There will be no difference between the reluctance components of students enrolled in different colleges.

Null Hypothesis No. 3: There will be no difference between the reluctance factors of students based on the number of credit hours they completed.

Null Hypothesis No. 4: There will be no difference between the reluctance profiles of students with high and low GPAs.

Null Hypothesis No. 5: There will be no difference between the reluctance components of students based on their year of enrollment at the university.

Results of the Data Analysis in Relation to the Research Question

A Pearson correlation matrix of the $40 \mathrm{OHQ}$ items was run yielding a Cronbach's alpha coefficient of .92 $(\alpha=.92)$. The 40 -item questionnaire was then subjected to factor analysis using principal axis factoring to extract the underlying factors. The varimax method was used to rotate the factor matrix. Data from the 40-item OHQ was analyzed using principal axis factoring (SPSS 16.0) to extract the underlying factors. The number of factors extracted was based on minimum eigenvalues of 1.0 and minimum loadings of .41 of individual items under each factor. The varimax rotation method produced a sevenfactor solution, accounting for approximately $59 \%$ of the total variance.

Factor 1 consisted of eight items, all of which reflected professors' competence and demeanor. The following eight items loaded on Factor 1 :

Loading

I'm motivated to attend office hours because of the way my professor treats students. $\quad .76$

I don't go to office hours because my professor doesn't take them seriously.

My professor's style of communicating with students encourages me to attend his/her $\quad .80$ office hours.

I don't see the need to attend office hours since my professor is unable to explain the lesson $\quad .63$ clearly.

I would like to go to office hours but my I'm afraid my professor will not show interest in $\quad .53$ helping me.

Semmar, Y. (2009). A Cross-Cultural, Exploratory Study of Students' Reluctance to Attend Office Hours. Learning and Teaching in Higher Education: Gulf Perspectives 6(1). http://www.zu.ac.ae/Ithe/Ithe06_01_02_semmar.htm 
I have no desire to go to office hours since the professor never encourages students to .57 attend.

I go to office hours because my professor emphasizes their importance.

I'm encouraged to go to office hours because I feel like the professor is able to pass .48 information on to students.

Factor 2 consisted of five items that reflected students' social skills. The following five items loaded on Factor 2:

Loading

Although I'd like to go to office hours, I feel like I can't because I am too shy to talk to my $\quad .82$ professors.

I don't go to office hours because I feel embarrassed.

I wish I could go to office hours, but I'm unable to interact with my professors.

It's difficult for me to go to office hours because I can't talk to my professors alone.

I avoid going to office hours because I feel anxious when I talk to my professors.

Factor 3 consisted of six questionnaire items that represented course characteristics:

There is no need for me to go to office house since I understand everything in the course. $\quad .76$

I go to office hours because I usually have questions about the course.

I don't need to go to office hours because the course is easy.

Most questions I have about the course are discussed in class, so I don't feel the need to go .68 to office hours.

I go to office hours because I need help from my professor

I don't go to office hours because there is nothing difficult about the course.

The four items that loaded onto Factor 4 made up participants' attitudes and motivation not to attend office hours:

I need to go to office hours because I will fail this course if I don't attend.

I don't go to office hours because I don't care about the course.

I do not want to go to office hours because there is no benefit.

I like to go to office hours because I care about the university.

Factor 5 consisted of two items that represented students' physical/emotional state: 
The two items that loaded on Factor 6 reflected participants' apprehension about attending office hours:

I don't go to office hours because I don't want to bother my professor.

I am encouraged to attend office hours because I know that my presence will not annoy $\quad .72$ the professor.

The four items that loaded on Factor 7 reflected participants' time conflict and communication style:

Loading

I don't go to office hours since I communicate with my professors via email whenever I $\quad .57$ have questions.

I would like to go to office hours but I cannot due to the timing conflict with my class .40 schedule.

I am unable to attend office hours because I'm busy with my other courses.

I don't go to office hours because I call my professor whenever I have questions about the $\quad .52$ course.

\section{Summary of the results of the 40 -item Factor Analysis}

Results of the factor analysis pointed to a distinct, seven-factor solution. Factor 1 consisted of items that reflect professors' competence and demeanor; factor 2 was comprised of items that represented students' social skills; factor 3 represented course characteristics; factor 4 symbolized students' attitudes and motivation; factor 5 consisted of participants' physical and emotional state; factors 6 represented students' apprehension to attend office hours; and factor 7 was related to students' communication style and time conflict, which made them reluctant to attend office hours.

In sum, results of the factor analysis portion of this study suggested seven components that characterize Qatari University students' reluctance to attend office hours (see Table 1):

\begin{tabular}{|l|l|l|l|l|}
\hline Factor & Label & Eigenvalue & Variance & Cumulative Variance \\
\hline 1 & $\begin{array}{l}\text { Professors' Competence/ } \\
\text { Demeanor }\end{array}$ & 10.062 & 21.154 & 21.154 \\
\hline 2 & Students' Social Skills & 3.694 & 9.235 & 34.390 \\
\hline 3 & Course Characteristics & 3.100 & 7.751 & 42.141 \\
\hline 4 & Students' Attitudes/Motivation & 2.190 & 5.474 & 47.615 \\
\hline
\end{tabular}

Semmar, Y. (2009). A Cross-Cultural, Exploratory Study of Students' Reluctance to Attend Office Hours. 


\begin{tabular}{|l|l|l|l|l|}
\hline 5 & Physical/ Emotional State & 1.712 & 4.279 & 51.894 \\
\hline 6 & Apprehension & 1.432 & 3.580 & 55.475 \\
\hline 7 & $\begin{array}{l}\text { Time Conflict/ Communication } \\
\text { Style }\end{array}$ & 1.356 & 3.390 & 58.865 \\
\hline
\end{tabular}

Table 1: Factor structure.

\section{Results of the Data Analysis in Relation to the Research Hypotheses}

In the second phase of the study, a causal-comparative design was employed to investigate the effects of gender, GPA, year of enrollment, college/major, credit hours completed, and English proficiency level on those seven reluctance factors. One-way MANOVA tests were used to examine the effects of gender, GPA, year of enrollment, college/major, and credit hours completed on the seven components that account for students' reluctance to attend office hours: Professors' competence/demeanor; students' social skills, course characteristics, students' attitudes/motivation; physical/emotional state; apprehension; and time conflict/communication style. Significant effects were found only for GPA, gender, and credit hours completed. The figures below show the results of the three, one-way MANOVAs for each of the seven reluctance components using the predictor variables of gender, GPA, and credit hours completed.

Results in Table 2 reveal a significant effect of gender on three of the seven reluctance factors: Physical/emotional state $(F=5.280, p<.05)$, students' attitudes/motivation $(F=5.272, p<.05)$, and students' social skills $(F=6.741, p<.05)$.

\begin{tabular}{|c|c|c|c|c|}
\hline Source & Dependent Variable & $d f$ & $\boldsymbol{F}$ & $p$ \\
\hline \multicolumn{5}{|c|}{ Between subjects } \\
\hline \multirow[t]{3}{*}{ Gender } & Physical/Emotional State & 2 & 5.280 & $.006 *$ \\
\hline & $\begin{array}{l}\text { Students' } \\
\text { Attitudes/Motivation }\end{array}$ & 2 & 5.272 & $.006^{*}$ \\
\hline & Students' Social Skills & 2 & 6.741 & $.001 *$ \\
\hline
\end{tabular}

Table 2: One-way MANOVA: Gender and office hours reluctance ( $\left.{ }^{*} p<.05\right)$.

With respect to participants' GPA, there were significant effects in relation to time conflict/ communication channel $(F=4.251, p<.05)$, physical/ emotional state $(F=5.514, p<.05)$, students' attitudes/motivation $(F=3.138, p<.05)$, course characteristics $(F=3.680, p<.05)$, and students' social skills $(F=3.866, p<.05)$ (see Table 3 ). There were no significant main effects on the other two reluctance components.

\begin{tabular}{|l|l|l|l|l|}
\hline Source & Dependent Variable & $d f$ & $\boldsymbol{F}$ & $\boldsymbol{p}$ \\
\hline \multicolumn{6}{|c|}{ Between subjects } & 3 & 4.251 & $.006^{*}$ \\
\hline GPA & Time Conflict/ Communication Channel & 3 &
\end{tabular}

Semmar, Y. (2009). A Cross-Cultural, Exploratory Study of Students' Reluctance to Attend Office Hours. 


\begin{tabular}{|l|l|l|l|l|}
\hline & Physical/ Emotional State & 3 & 5.514 & $.001^{*}$ \\
\hline & Students' Attitudes/ Motivation & 3 & 3.138 & $.027^{*}$ \\
\hline & Course Characteristics & 3 & 3.680 & $.013^{*}$ \\
\hline & Students' Social Skills & 3 & 3.866 & $.010^{*}$ \\
\hline
\end{tabular}

Table 3: One-Way MANOVA: GPA and Office Hours Reluctance ( $\left.{ }^{*} p<.05\right)$.

Credit hours completed shows a significant effect on only one of the seven reluctance components: Time conflict/communication channel $(F=5.878, p<.05)$.

\section{Discussion}

The study has shown that the reluctance of Qatar University students to attend office hours seems to be related to Professors' perceived competence/demeanor; students' social skills, course characteristics, students' attitudes/motivation; physical/emotional state; apprehension; and time conflict/communication channel.

\section{Professors' perceived competence/ demeanor}

Professors' competence/ demeanor was shown to play a major role by accounting for a great proportion of the explained variance in students' reluctance to attend office hours. This dimension involves a number of characteristics related to professors, such as their pedagogical competence, the manner with which they treat students and relate to them, and the role they play in encouraging students to attend office hours and emphasizing their importance. In her study of factors affecting the achievement of minority students, Wilson (1997) found that when students perceived their professors as approachable, humane, and caring, they were much more likely to seek help from them and get motivated about the course content. Nearly four decades ago, Rogers (1969) asserted that the realness or genuineness of teachers serves as a catalyst to significant, pervasive learning, which can have a positive impact on students' behaviors, attitudes, and personalities.

\section{Students' social skills}

Students' social skills are another factor that affects students' willingness to attend office hours. Many students at Qatar University seem to lack the basic interpersonal skills that enable them to communicate with their professors outside of the classroom context. The female student population, in particular, seems to be reserved and shy especially towards seeking help or advice from their male professors. The latter might be a reflection of a broader cultural context in Qatari society where children are socialized in distinct gender roles and in which the social fabric of households tends to keep the female "element" relatively distant from its male "counterpart," which, in turn, might explain the significant effect of gender that was revealed in this study vis-à-vis students' social skills. McKeage (2001) has noted that establishing electronic office hours is likely to help students participate in the academic discourse as well as improve their communication skills which are deemed essential for their personal and professional development. In the same vein, electronic office hours can make it less intimidating for some students to communicate their concerns/needs as compared to doing so in person during the "traditional" office hours (Kussmaul et al., 1996). 


\section{Course characteristics}

Results from this study showed that students are unlikely to attend office hours if all their needs related to the course content, materials, and assignments are met. They are also likely to feel reluctant to seek help from their professors if they perceive that the course is "easy" and that all of their questions and inquiries about the course are answered in the classroom. A significant effect of gender on course characteristics was also noted in the study. From my experience at Qatar University, it is students with high GPAs who usually come to office hours to seek additional help or guidance with their course assignments and projects. Conversely, those deemed "at risk" with low GPAs are notorious for avoiding coming to office hours to seek assistance (Ryan et al., 1998).

\section{Students' attitudes/motivation}

This study revealed that students are most likely to become very reluctant and resistant to seek help from their instructors during office hours if they do not seem to care about the course and the university, do not perceive any immediate benefit from attending office hours, and believe they were going to fail the particular course regardless. Wilson (1997) maintained that many minority students lack the necessary motivation to learn the materials of their university courses. As a result,

"the motivation that many minority students rely on is to a great extent the personal relationship

that develops between themselves and the cultural agent who transmits the material" (p. 535).

Moreover, when students doubt their abilities to succeed in their school work, they are likely to avoid seeking help from their teachers when they need it (Ryan et al., 1998). A significant gender effect was also revealed in relation to students' attitudes/motivation towards attending office hours. A previous study looking at gender differences in motivation among Qatari university students demonstrated that males, in general, tend to be less motivated towards their university courses and hold more negative attitudes towards the university as compared to their female counterparts (Semmar, 2007).

\section{Physical/emotional state}

This component reflected participants' unwillingness to attend office hours due to their physical/emotional state. This was reflected in students feeling tired and overstrained with the daily university demands while on campus as well as the need to walk long distances to see their professors whose offices might be located in distant venues, all of which can understandably be applicable to both genders. However, in terms of the desire to leave campus as soon as classes are over, male students are more able to do so because the vast majority of them drive to campus independently, so they are free to leave the university grounds whenever they want. This is not possible for the female cohorts since they are typically driven (chaperoned) to campus by their fathers, brothers or drivers, and are not allowed to leave campus until their ride arrives. Wanting to leave campus as soon as possible might be due to the fact that there are insufficient extracurricular activities and resources that attract students' interest, or that they might lack a sense of belongingness to the university community, which can further affect their attitudes and motivation towards their courses (Maslow, 1970).

\section{Apprehension}

The Qatar University student population sampled in this study believed that their presence during office hours represents somewhat of a burden or nuisance to their professors. Still many others feel anxious about individually approaching their instructors or communicating with them outside of the classroom context. This source of apprehension might be related to various factors, such as fear of being rejected, past experiences with other professors, and certain attitudes and behaviors that convey to students that

Semmar, Y. (2009). A Cross-Cultural, Exploratory Study of Students' Reluctance to Attend Office Hours. 
their professors are unapproachable. Wilson (1997) found that minority students tend to encounter difficulties when they attempt to ask for help from their instructors during office hours. One of them expressed those feelings in the following way:

"I remember walking to his office like five times, going to his door, and I couldn't knock. I couldn't do it. It was so scary. I didn't know what he was going to say. All I knew that his name was Professor X, but I didn't know what kind of a person he was. He never did meet me, I never did meet him" ( $p$. 541).

While there seems to be a similarity in students' attitudes towards office hours between U.S. minority students (as reported in the aforementioned studies) and Qatari university students, it is essential to emphasize that these latter make up the majority of the university student body. Moreover, it is important to note in this regard that Qatar is considered a collectivistic society where students are used to and more comfortable doing things in groups. For instance, whether be it in the university cafeterias, library, hallways, student activity centers, rarely does one see students sitting down by themselves or engaging in activities alone. Therefore, going to see a professor individually during office hours might seem a relatively new concept or "culture" in this educational setting. In a recent study, Chung and Hsu (2006) supplemented office hours with a "course center" where students, who might feel intimidated about individually attending office hours, can come interact with their peers and hear them ask questions to their instructors. This learning community atmosphere, the authors explain, is likely to convey to those anxious students the message that they are not alone when it comes to needing assistance with their course assignments.

\section{Time conflict/ communication channel}

Students' time conflict/ communication channel was the final component that contributed to their reluctance to attend office hours. Oftentimes, students are unable to visit their professors during office hours because the times of the latter conflict with other engagements, such as attending course lectures and going on field-trips. It is perhaps because of this time conflict issue that some students prefer to contact their professor via other means, such as e-mail and telephone. Moreover, the fact that the number of credit hours completed had a significant effect on this reluctance factor in this study suggests that students who are in their senior year might not always find it suitable to seek help from their professor during prescribed office hours because of their final course requirements and projects. On the other hand, one might argue that it is because of these very final year demands that senior students are likely to go "the extra mile" to find the necessary time to visit their professors during office hours.

\section{Recommendations}

This study was based on exploring the factors that make Qatari university students reluctant to attend office hours. A future study may be helpful in terms of examining the stability of the seven reluctance components over time. Further research should also focus on how those seven factors relate to each other. Certain statistical paradigms, such as path analysis, might be helpful in terms of delineating the causal relationships between students' social skills, apprehension, time conflict/communication channel, course characteristics, attitudes/motivation, physical/emotional state, and professors' competence/demeanor. Moreover, since gender, GPA, and credit hours completed all had significant effects on several of the reluctance factors, it will be important to further investigate and understand the relationship between the seven reluctance factors and students of different gender, those with low GPAs (i.e., "at risk") and high GPAs, and those in different enrollment standing (i.e., freshmen, sophomore, junior, senior). Finally, it would be equally worthwhile to examine the attitudes and beliefs

Semmar, Y. (2009). A Cross-Cultural, Exploratory Study of Students' Reluctance to Attend Office Hours. 
of faculty members and departments towards both the importance of office hours as well as the reasons underlying students' reluctance to seek help or interact with them outside of the classroom context.

\section{Conclusion}

Data from this study suggest that reluctance of Qatar University students to attend office hours was influenced by professors' competence/demeanor, social skills, apprehension, time conflict/communication channel, course characteristics, attitudes/motivation, and physical/emotional state. Students are more likely to be motivated to attend office hours and seek help from their professors when they view them as caring, humane, and genuine (Wilson, 1997). When instructors take the time to explain to students the importance and benefits of attending office hours, when they explicitly and implicitly convey to students that they care about their success and encourage them to seek assistance whenever the need arises, students will more likely perceive them as approachable and will less likely feel anxious to pay them a visit in their office.

Organizing workshops to help students improve their interpersonal skills and time management skills might provide them with the confidence to know how to better interact with their professors outside of the classroom context and seek assistance from them. Since the concept of "office hours" is relatively new to this educational setting, it might be a good idea for faculty members to highlight to students the importance of coming prepared with specific questions/inquiries in order to attain the maximum benefit from their office hours visit. In the same vein, because some students (especially females) might still feel awkward about going to office hours alone, faculty members might consider holding "group office hours" in order to ease the initial process of interacting with these types of students outside of the classroom walls. Finally, holding office hours electronically or supplementing "traditional" office hours with electronic modes of communication (e.g., e-mail and Blackboard technology) might serve as an extra vehicle to ensure that students' needs are met outside of the classroom (Griffin \& Anderton-Lewis, 1998; DeCerce, 2001).

\section{References}

Amenkhienan, C. A, \& Kogan, L. R. (2004). Engineering students' perceptions of academic activities and support services: Factors that influence their academic performance. College Student Journal, 38 (4), 523-534.

Astin, A. (1977). Four critical years: Effects of college on beliefs, attitudes and knowledge. San Francisco: Jossey-Bass.

Atamian, R., \& DeMoville, W. (1998). Office hours - none: An e-mail experiment. College Teaching, 46 (1), 31-36.

Chickering, A. (1969). Education and identity. San Francisco: Jossey-Bass.

Chickering, A. (1972). Undergraduate academic experience. Journal of Educational Psychology, 63(2), 134-143.

Chickering, A., \& McCormick, J. (1973). Personality development and the college experience. Research in Higher Education, 1, 43-70.

Chung, C., \& Hsu, L. (2006). Encouraging students to seek help: Supplementing office hours with a course center. College Teaching, 54 (3), 253-260.

Semmar, Y. (2009). A Cross-Cultural, Exploratory Study of Students' Reluctance to Attend Office Hours. Learning and Teaching in Higher Education: Gulf Perspectives 6(1). 
DeCerce, J. (2001). Students and faculty on same wavelength at SUNY Morrisville. T H E Journal, 28 (8), 25-26.

Griffin, F. W., \& Anderton-Lewis, L. (1998). Enhancing connections between students and instructors: African-American students' use of computer-mediated communication. Business Communication Quarterly, 61 (2), 9-14.

Kussmaul, C., Dunn, J., Bagley, M., \& Watnik, M. (1996). Using technology in education: When and why, not how. College Teaching, 44 (4), 122-126.

Maslow, A. (1970). Motivation and personality. New York: Harper \& Row.

McKeage, K. (2001). Office hours as you like them. College Teaching, 49 (1), 23-32.

Nadler, M. K., \& Nadler, L. B. (2000). Out of class communication between faculty and students: A faculty perspective. Communication Studies, 51 (2), 166-176.

Onwuegbuzie, A. J., Witcher, A. E., Collins, K. M. T., Filer, J. D., \& Moore, C. W. (2007). Students' perceptions of characteristics of effective college teachers: A validity study of a teaching evaluation form using a mixed-method analysis. American Educational Research Journal, 44 (1), 113-160.

Pascarella, E. T. (1980). Student-faculty informal contact and college outcomes. Review of Educational Research, 50, 545-595.

Pascarella, E. T., \& Terenzini, P. T. (1976). Informal interaction with faculty and freshmen ratings of the academic and non-academic experience of college. Journal of Educational Research, 70, 35-41

Pascarella, E. T., \& Terenzini, P. T. (1991). How college affects students. San Francisco: Jossey-Bass.

Pascarella, E. T., \& Terenzini, P. T., \& Hibel, J. (1978). Student-faculty interaction settings and their relationship to predicted academic performance. Journal of Higher Education, 49, 450-463.

Rogers, C. R. (1969). Freedom to Learn. Columbus, OH: Charles E. Merrill.

Ryan, A. M., Gheen, M. H., \& Midgley, C. (1998). Why do some students avoid asking for help? An examination of the interplay among students' academic efficacy, teachers' social-emotional role, and the classroom goal structure. Journal of Educational Psychology, 90 (3), 527-535.

Semmar, Y. (2007). Gardner's socio-educational model of second language acquisition: Alive and well in two foreign language-learning contexts. Lingua et Linguistica, 1(2), 174-188.

Shadish, W. R., Cook, T. D., \& Campbell, D. T. (2002). Experimental and quasi-experimental designs for generalized causal inference. Boston, MA: Houghton Mifflin.

Spady, W. (1970). Dropouts from higher education: An interdisciplinary review and synthesis. Interchange, 1, 64-85.

Spady, W. (1971). Dropouts from higher education: Toward an empirical model. Interchange, 2, 38-62.

Theophilides, C., \& Terenzini, P. T. (1981). The relation between nonclassroom contact with faculty and students, perceptions of instructional quality. Research in Higher Education, 15, 255-269.

Wilson, P. (1997). Key factors in the performance and achievement of minority students at the University of Alaska, Fairbanks. American Indian Quarterly, 21 (3), 535-544.

Wilson, R. C., Woods, L., \& Gaff, J. G. (1974). Social-psychological accessibility and faculty-student interaction beyond the classroom. Sociology of Education, 47, 74-92.

Semmar, Y. (2009). A Cross-Cultural, Exploratory Study of Students' Reluctance to Attend Office Hours. 
Wood, L., \& Wilson, R. (1972). Teachers with impact. The Research Reporter, 7, 1-4.

\section{Author}

Dr. Yassir Semmar is Assistant Professor of psychology in the College of Education at Qatar University. Dr. Semmar has previously taught at the UAE University and California State University, Long Beach. His research interests include e-learning practices in higher education, cognitive/affective variables in language acquisition, and students' attitudes towards seeking psychological help. 